\title{
Dynamic response of underpasses for high-speed train lines
}

\author{
J. Vega ${ }^{a, *}$, A. Fraile ${ }^{\text {b }}$ E. Alarcon ${ }^{\text {b }}$, L. Hermanns ${ }^{b}$ \\ a CEMIM-F2I2, Jose Gutierrez Abascal 2, 28006 Madrid, Spain \\ b ETSII, Universidad Politecnica de Madrid, Jose Gutierrez Abascal 2, 28006 Madrid, Spain
}

\begin{abstract}
A B S T R A C T
Underpasses are common in modern railway lines. Wildlife corridors and drainage conduits often fall into this category of partially buried structures. Their dynamic behavior has received far less attention than that of other structures such as bridges, but their large number makes their study an interesting challenge from the viewpoint of safety and cost savings. Here, we present a complete study of a culvert, including on-site measurements and numerical modeling.

The studied structure belongs to the high-speed railway line linking Segovia and Valladolid in Spain. The line was opened to traffic in 2004. On-site measurements were performed for the structure by recording the dynamic response at selected points of the structure during the passage of high-speed trains at speeds ranging between 200 and $300 \mathrm{~km} / \mathrm{h}$.

The measurements provide not only reference values suitable for model fitting, but also a good insight into the main features of the dynamic behavior of this structure. Finite element techniques were used to model the dynamic behavior of the structure and its key features. Special attention is paid to vertical accelerations, the values of which should be limited to avoid track instability according to Eurocode. This study furthers our understanding of the dynamic response of railway underpasses to train loads.
\end{abstract}

\section{Introduction}

The analysis of the dynamic response of bridges traversed by moving loads has a long tradition in civil engineering. Since the first contributions by Willis [1], Stokes [2], Timoshenko [3], Inglis [4], and others, numerous authors and institutions have contributed to this topic. With the introduction of the digital computer, it became possible to analyze more complicated problems, such as those described by Hilleborg [5] Biggs [6] and Fryba [7].

The research in this field has provided highly valuable results, enabling accurate design with reasonable effort. For instance, in the case of high-speed lines (HSL), the standard reference is the European Rail Research Institute publication [8]. This report provides formulae for estimating the impact coefficient.

With the introduction of commercial high-speed lines, it was observed that short-span bridges were sensitive to highspeed trains, displaying important accelerations [9]. Then, the idea arose of connecting the abutments with the beams, i.e., designing frames and closed frames to take advantage of the dissipative capacity of the backfill to increase the global damping and consequently reduce the bridge response.

The distinction between culverts and short-span bridges was not clear, and a concern was raised regarding whether culverts were affected by higher speeds. It is interesting to note that underpasses are often used. Railway networks run 
long distances with very restrictive geometric constraints (e.g., gradients, alignment, curvature, radius), making crossing through a large variety of topographical difficulties unavoidable. Culverts are used for a large variety of crossings, including drainage conducts, wildlife corridors, and roads of low and medium importance underpasses.

In general, these small infrastructures have never been considered worth an in-depth structural analysis, except for the so-called soil-steel bridges [10,11], where the flexibility of the conduit wall presents an interesting challenge to the designer from the viewpoint of soil-structure interactions. When concrete is used, the design is often executed in a routine fashion. Designers may forget that although the individual cost is low, the large number of culverts on a typical HSL makes the avoidance of any structural problems an economically worthwhile objective.

The dynamic analysis of the soil-structure interaction of a frame supporting an HSL is challenging, even from a purely scientific viewpoint. Therefore, guidelines (eventually a code) should be provided to designers to complement the existing Eurocodes, which state checks for stresses and fatigue, but also for maximum peak acceleration beneath the ballast in order to prevent its liquefaction ([12,13]).

The primary goal of this paper is to set a model that is able to reproduce the dynamic behavior of an underpass, the response variables of interest being not only strains in the structure but also accelerations, due to the observed possibility of ballast liquefaction in existing HSL. Once the model set, the possibility of making simplifications will be discussed, in order to get to less complex models appropriate for parametric studies, as well as for practical design purposes.

Several authors previously attempted to develop a simplified design method using advanced boundary element methodology [14], but at that time, it was impossible to find published results reporting in-situ measurements against which to verify the theoretical results. Examples in the literature include mixed boundary element-finite element modeling both for culverts [15] or short span bridges [16], but again, no validation against measurements has been presented. We concluded that it was necessary to perform an in-situ test campaign on existing underpasses. The recently built HSL between Segovia and Valladolid was selected for this purpose. Partial results have been presented elsewhere $[17,18]$.

In this study, finite element techniques were used to model the dynamic behavior of a sample underpass on an HSL. This structure was selected because its dimensions were found to be the most common for this sort of railway line. First, a comprehensive review of the main results of the test campaign is presented. An analysis of the recordings revealed the response distribution pattern along the roof-slab. Next, a substructuring method using a set of two finite element (FE) models is shown to adequately model the dynamic soil-structure interaction. Finally, one of the FE models is simplified to reduce the computational cost at the price of limiting the scope of the analysis to the portion of the structure under the highest demand.

\section{Structure description and layout}

The structure selected for monitoring has a square box cross-section. Its inner opening is $3 \mathrm{~m}$ in width, and the walls are $0.2 \mathrm{~m}$ thick. It is constructed by eight precast blocks, each $2 \mathrm{~m}$ in length. Therefore, the total length of the structure is $16 \mathrm{~m}$. The continuity across blocks is assured since each block has in-wall rebated joints, whose efficiency has been confirmed by the tests.

The structure is laid on a $10 \mathrm{~cm}$ thick layer of blinding concrete. The available geotechnical information indicates that the pre-existing soil is granular, with a medium to high density. The standard penetration test (SPT) varies almost linearly from 10 at $1 \mathrm{~m}$ depth, to 90 at $5 \mathrm{~m}$. The embankment, as the whole line, was entirely new when the line was opened to traffic.

A statistical analysis of the inventory of all culverts and underpasses in the HSL linking Segovia and Valladolid revealed the studied cross-section to be the most commonly found, constituting almost 50 percent of square-shaped, closed-box frames. Three other factors led to the choice of this structure: its near perpendicularity to the track axis, its reduced overburden, and the topological conditions of the surroundings, which allowed both suitable access and good visibility of the arriving train while conducting the tests.

The structure and superstructure were both monitored with piezoelectric accelerometers. The structure was instrumented with six sensors placed in the middle sections of each of three different precast blocks (c.f. Fig. 1). Three of these sensors (Sensors A, B, and C) recorded the vertical acceleration at the midline of the roof-slab, and three others (Sensors I, J, and $\mathrm{K}$ ) recorded the horizontal acceleration at the middle height of one sidewall.

In the superstructure, the sensors were placed vertically on the sleepers, close to the exterior rail-pads, and on the rail foot at midspan between two sleepers (c.f. Fig. 1). Four pairs of sleeper and rail sensors were placed, two on each track. In each case, one sleeper was placed approximately over the midspan of the underpass, and the other was placed three sleepers further toward the north (Valladolid). Sleeper distance is $0.6 \mathrm{~m}$.

In this paper, we focus on the dynamic response of the underpass roof-slab; thus, only measurements from Sensors A, B and $\mathrm{C}$ in Fig. 1 are discussed.

\section{Summary of the monitoring results}

The structure was monitored for slightly more than $24 \mathrm{~h}$. During that time, 46 trains traveled on the line. This line is used by four different types of high-speed trains. Their nominal axle loads and distances are presented in Fig. 2. The 


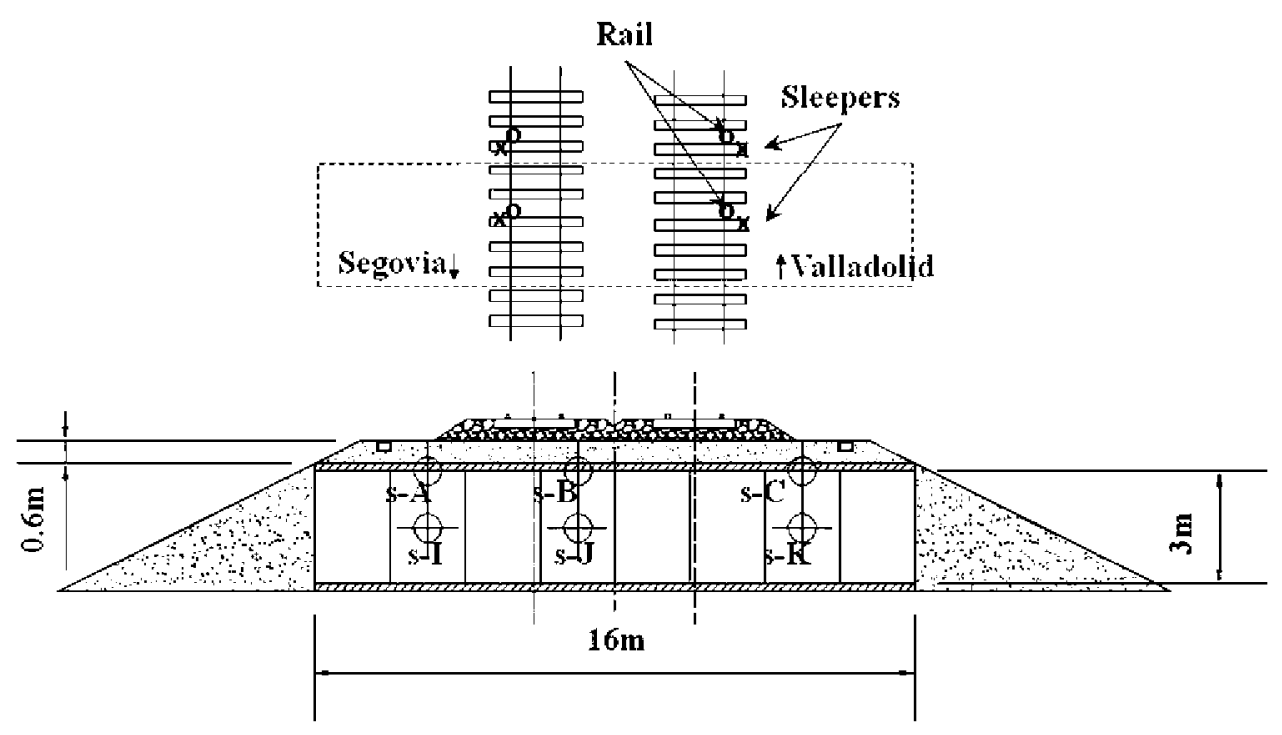

Fig. 1. Structure geometry and sensor positioning.

(a)

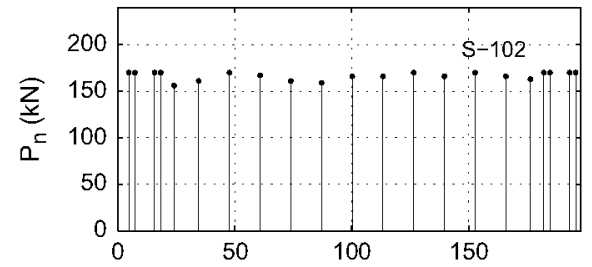

(c)

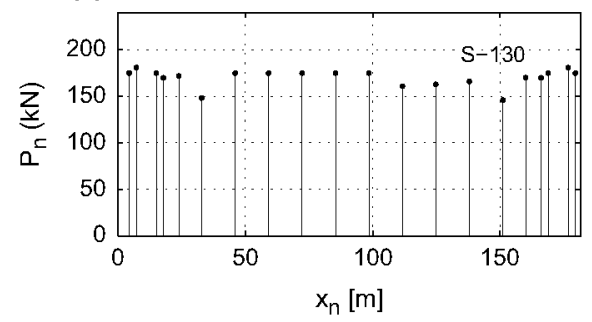

(b)

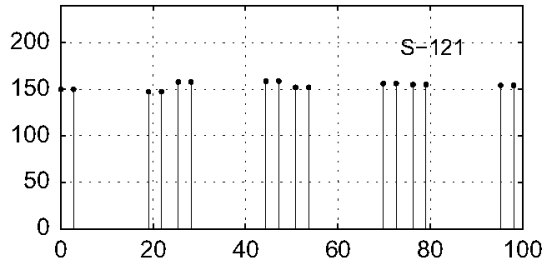

(d)

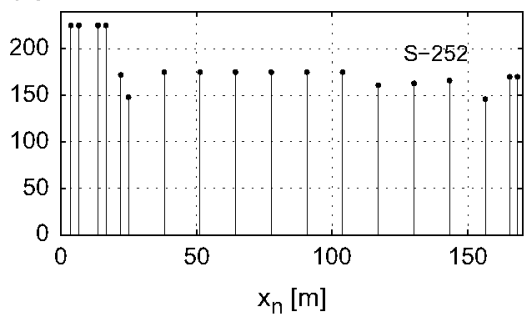

Fig. 2. Axle loads and distributions for the four trains traveling the line: (a) S-102, (b) S-121, (c) S-130 and (d) S-252.

Table 1

Codes (commercial and Renfe) and maximum speeds for all observed train types.

\begin{tabular}{lllll}
\hline RENFE code & S-102 & S-121 & S-130 & S-252 \\
Commercial code & Talgo 350 & ATPRD & Talgo 250 & Talgo s-VII \\
Max. speed $(\mathrm{km} / \mathrm{h})$ & 330 & 250 & 250 & 220 \\
\hline
\end{tabular}

commercial names linked to RENFE codes and maximal speeds are listed in Table 1 . The so-called S-252 trains are quite different from the others because of their heavy locomotives. S-102 trains operate only on high-speed lines, while the S-121 and S-130 trains have variable-width bogies, allowing them to use both the Spanish (1667 mm) and the UIC-gauge (1435 mm) networks. S-252 trains lie in between both cases: the carriages have variable-width, while the locomotives do not, and need to be removed each time the train changes the network.

A sample of the acceleration time histories obtained is shown in Fig. 3. These data were recorded during the passage of an S-121 train in double configuration, from Valladolid to Segovia, with an estimated speed of $220 \mathrm{~km} / \mathrm{h}$. Speeds were estimated in two ways: from video recordings of the trains during the tests and by measuring the time lapses between peaks associated with each axle in the running root mean square (RMS) acceleration records. The acceleration records 
(a)

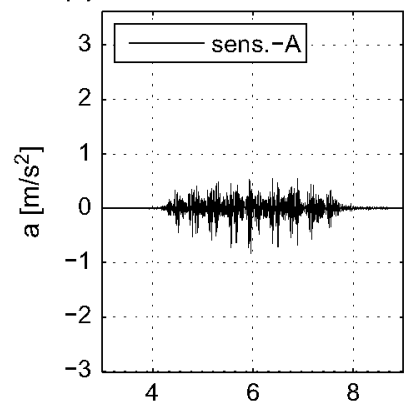

(d)

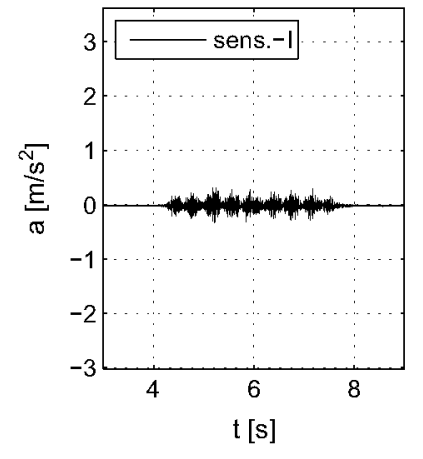

(b)

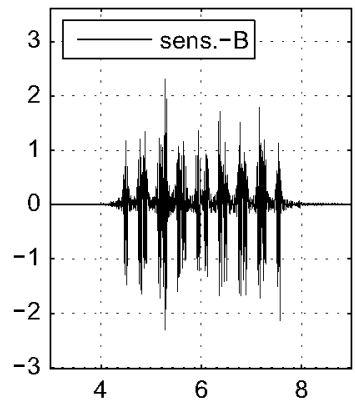

(e)

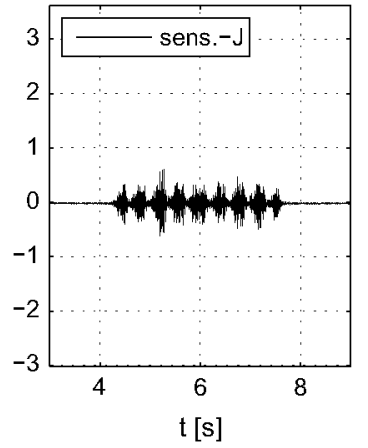

(c)

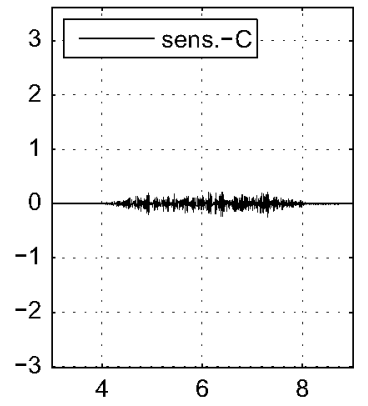

(f)

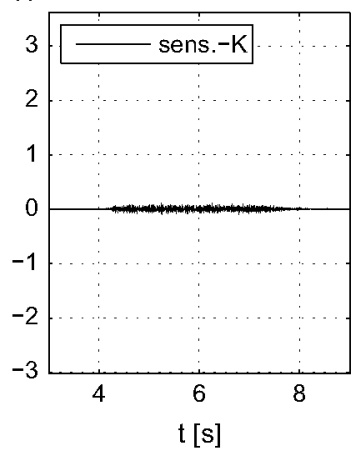

Fig. 3. Sample acceleration records for sensors on the roof (plots $a, b$ and c) and at the wall (plots d, e and f).

show important differences in measured levels depending on the sensor. In this case, the largest response was measured close to the roof-slab center.

A spectral analysis of this signal (c.f. Fig. 4) shows that the energy is distributed over a wide range between 0 and $120 \mathrm{~Hz}$ at the middle sensor position, and in a narrower range up to $60 \mathrm{~Hz}$ at the other two positions. The sidewall records also display important amounts of energy at frequencies up to $120 \mathrm{~Hz}$.

As will be shown in the following, the fundamental vibration mode of the roof-slab is close to $40 \mathrm{~Hz}$. This finding is interesting because ECO-A2 [12] indicates that peak acceleration levels must be calculated considering frequencies up to the greater of: (i) $30 \mathrm{~Hz}$; (ii) 1.5 times the frequency of the fundamental mode of vibration; (iii) The frequency of the third mode of vibration. In this case, it is difficult to establish the vibration modes of the structure-embankment ensemble. However, it is clear that the recorded signal exhibits an important amount of energy far above $1.5 \times 40=60 \mathrm{~Hz}$.

Fig. 5 represents, for each sensor, all of the recorded peak acceleration values as a function of train speed. Different symbols are used for each train type. Also, different symbols are used for trains traveling from Segovia to Valladolid (northbound) and for those going from Valladolid to Segovia (southbound).

Interestingly, the speeds for a given train type are similar in almost all cases. This is logical, considering that these trains are almost always operated at their nominal speeds. However, even when considering each group of similar samples (i.e., a given train at a given speed), there is always a large scatter in peak acceleration values. It is also clear that the track, in the direction of travel, is important for the response level, but this difference can be explained by the spatial load distribution arising from the plate effect of the roof-slab. Depending on the direction of travel, the relative distances between the sensor and the circulating track are different. Measurements obtained from both directions of travel can be considered together if this relative distance is considered. As shown in Fig. 6, when considering relative distances, the number of available positions for comparison increases because the central sensor is not symmetrically placed.

Fig. 7 presents a plot of peak vertical acceleration as a function of relative sensor position along the roof-slab of the underpass. To reduce all other sources of scatter, only S-130 trains traveling at approximately $200 \mathrm{~km} / \mathrm{h}$ were considered. The colors and symbols used are consistent with those in Fig. 5. From Fig. 7, for example, it is clear that at a position of $5 \mathrm{~m}$, both directions of travel led to similar acceleration levels, which confirms the importance of relative position in explaining the response values.

Fig. 7 shows the unequal distribution of acceleration responses along the longitudinal (perpendicular to the track) cross-section of the roof-slab. The demand is much greater below the occupied track than below the empty one, and the variation of the acceleration level shows the distribution arising from the plate effect of the roof-slab. The following section describes the FE models that were constructed to provide a more detailed description of this response. 
(a)

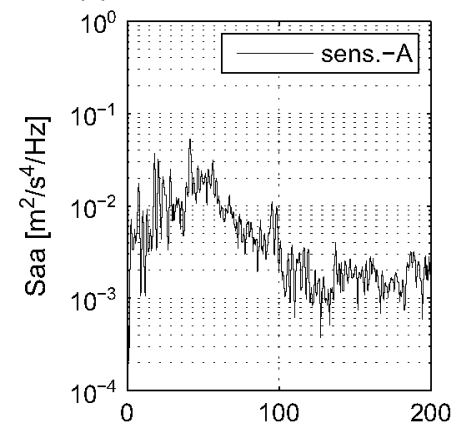

(d)

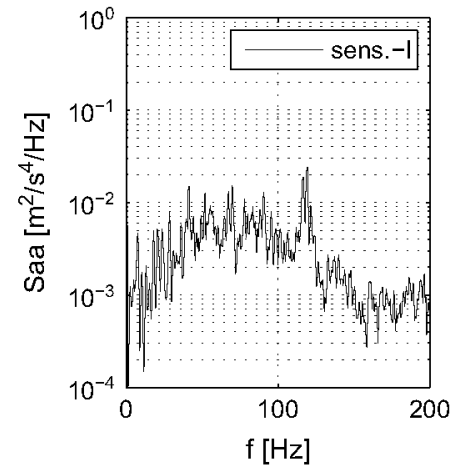

(b)

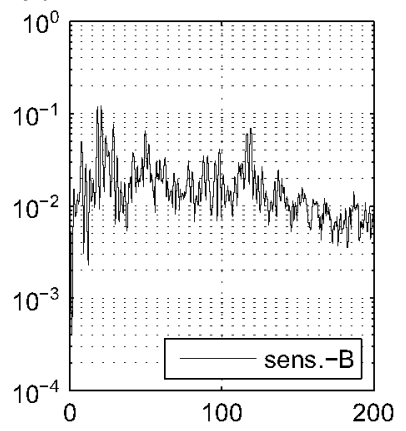

(e)

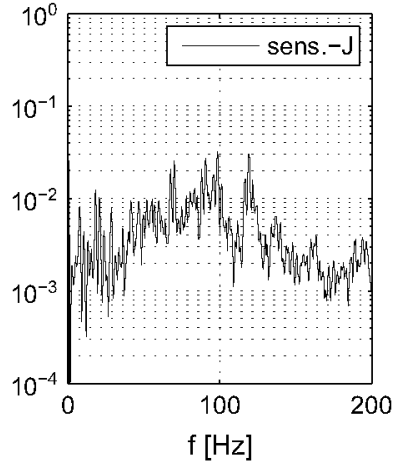

(c)

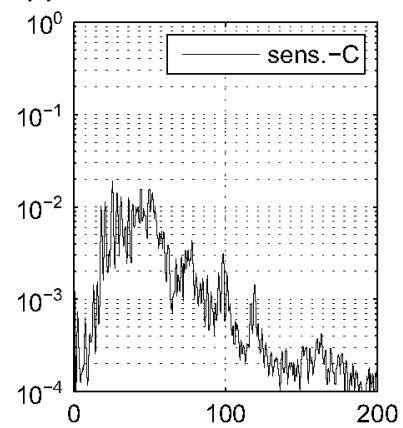

(f)

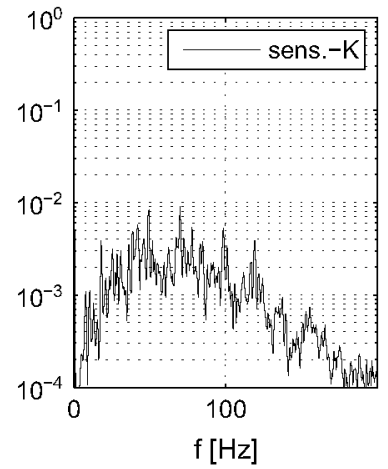

Fig. 4. Spectral densities for the recording presented in Fig. 3, on the roof (plots a, b and c) and at the wall (plots d, e and f).

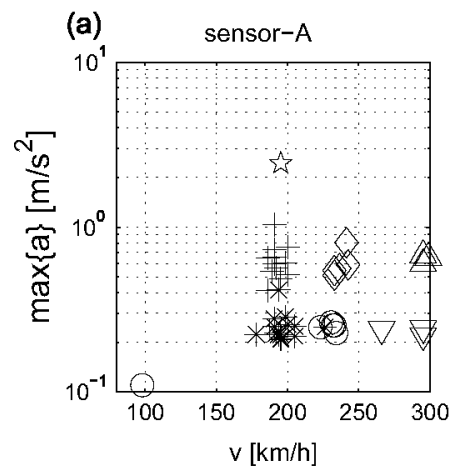

(b)

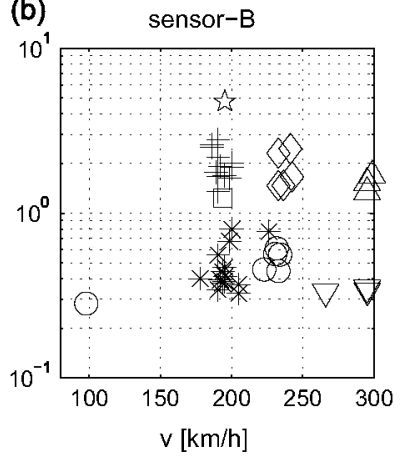

(c)

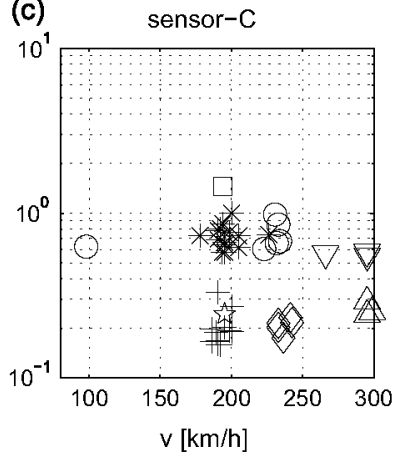

\begin{tabular}{|c|c|c|}
\cline { 2 - 3 } \multicolumn{1}{c|}{} & Seg. $\rightarrow$ Vall. & Vall. $\rightarrow$ Seg. \\
\hline S-121 & $\bigcirc$ & $\diamond$ \\
\hline S-130 & $*$ & + \\
\hline S-102 & $\nabla$ & $\triangle$ \\
\hline$S-252$ & $\square$ & $\downarrow$ \\
\hline
\end{tabular}

Fig. 5. Peak accelerations on the roof: (a) sensor $A$, (b) sensor $B$ and (c) sensor $C$.

Fig. 7 also shows the scatter among recordings for each given train and speed. Given the highly nonlinear wheel-rail dynamics and the link between peaks in acceleration and the high-frequency content of the signal, random impacts may be responsible for most of the scatter.

The coefficient of variation ( $\mathrm{CoV})$ provides a measure of this scatter. Considering only the records with highest responses, that is, recordings at the relative track-sensor position $+1 \mathrm{~m}, \mathrm{CoV}=33$ percent.

If instead of actual values, one considers their running root mean square (RMS) values, it is possible to get rid of the high-frequency content of the records, and therefore obtaining values that are less dependent on the nonlinearities of the 


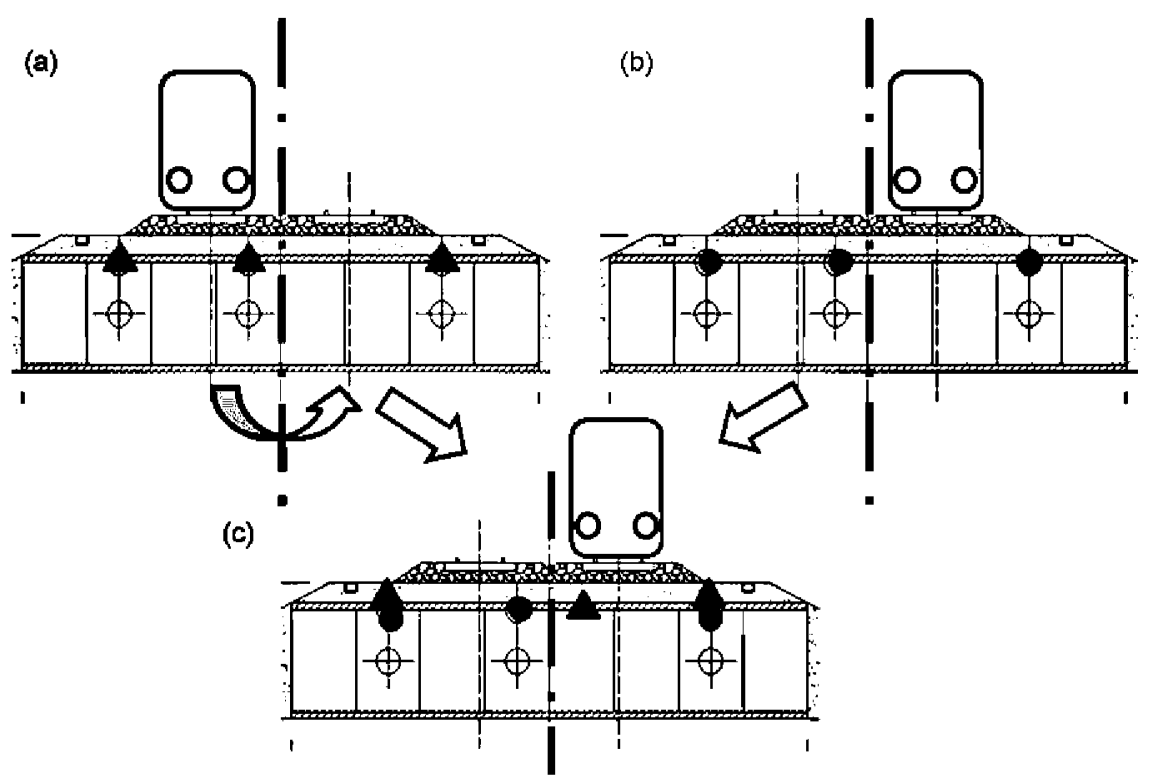

Fig. 6. Identification of the relative positions of sensors with respect to the track axis for trains traveling: (a) southbound, and (b) northbound. Plot $c$ shows relative positions considering a single reference track.

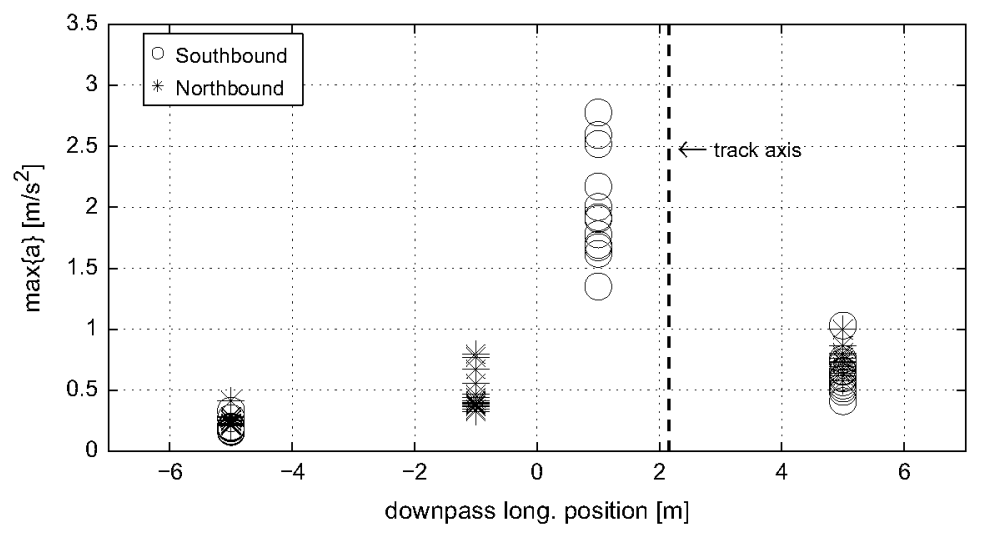

Fig. 7. Peak acceleration as a function of relative position along the transverse axis of the roof (considering only 5 - 130 trains traveling at approximately $200 \mathrm{~km} / \mathrm{h}$ ).

problem. If rectangular windows with length equal to $1 \mathrm{~s}$ are considered, the running RMS ' $a_{R M S, \tau=1 s}(t)$ is defined as

$$
a_{R M S, \tau=1 s}(t)=\sqrt{\int_{t}^{t+1} a^{2}(s) \mathrm{d} s} .
$$

Considering maxima among running RMS values the scatter is reduced to $\operatorname{CoV}_{\mathrm{RMS}}=15$ percent. This scatter is similar to that previously measured for accelerations in simply supported bridges on other HSLs [19].

To set up a model, the conclusions that have just been drawn about the response distribution and scatter are quite consequential. It seems pointless to select one record and look after a fine-tuned model, because it would only be suited for this particular event. Therefore modelers face two choices: either use deterministic mean models (fitting mean values) or use models having random parameters that should be able to produce results with similar scatter. The latter one has been the authors choice.

\section{Modeling}

Several procedures are available for analyzing the vibrations transmitted from an HSL. Some authors [15] prefer a direct approach at the price of accepting a trade-off between the different wavelengths at every point of the model, whereas the Federal Transit Administration (FTA) recommends a substructuring approach that allows the use of the most suitable model for every part of the problem [20]. 
In this study, vibration levels at different points of the system are predicted using the substructuring method [21] considering a model with two components (c.f. Fig. 8). First, for a given train and a given speed, the reaction force records against the sleeper soffit $f_{k}(t)$ are evaluated at $N_{s}$ discrete points beneath the axis of the rails. Those points are considered source terms in the second computational step, where the acceleration record $a(t)$ at the point of interest is obtained using Eq. (2), considering the impulse response functions $h_{k}(t)$ of each source point. The impulse response function is the acceleration produced at the point of interest due to a unitary pulse in the source point labeled $k$, and is calculated with a second model named the transmission model

$$
a(t)=\sum_{k=1}^{N_{s}} a_{k}(t)=\sum_{k=1}^{N_{s}} h_{k}(t) * f_{k}(t) .
$$

The * symbol in Eq. (2) indicates the time domain convolution.

\subsection{Emission model}

The first step, which provides reaction forces at discrete points below the sleepers, is performed using a finite element model that represents half of the track superstructure (c.f. Fig. 9). In this model, each soffit of a sleeper is considered a source point.

The rail is modeled using beam elements. The sleepers are modeled as lumped masses. Spring dashpot elements are used to indicate both the fastening system and the ballast-embankment ensemble. It should be emphasized that these elements account for the stiffness of everything below the ballast and make it possible to split the complete problem into two separate problems.

A lumped mass representing the unsprung mass of half an axle is set to move at the train's speed. A spring dashpot element is used to model wheel-rail contact, with the values $k_{h}=1.875 \times 10^{9} \mathrm{~N} / \mathrm{m}$ and $c_{h}=34.64 \times 10^{3} \mathrm{Ns} / \mathrm{m}$. A moving load representing the axle load is linked to this mass. The unsprung mass and axle load both depend on the considered train type. Rail roughness is represented by considering a profile consistent with Braun and Hellenbroich's spectral density model [22]:

$$
G_{r r}(n)=G_{r r}\left(n_{0}\right)\left(\frac{n}{n_{0}}\right)^{-\infty}
$$

where $n_{0}=1 /(2 \pi)$, and $\omega=3.5$.

For any given position of the unsprung mass, the mass, damping and stiffness matrices, as well as the load vector are synthesized. Time integration of the motion equation yields reaction force histories at discrete points of the sleeper's soffit. Newmark's average acceleration method was used.

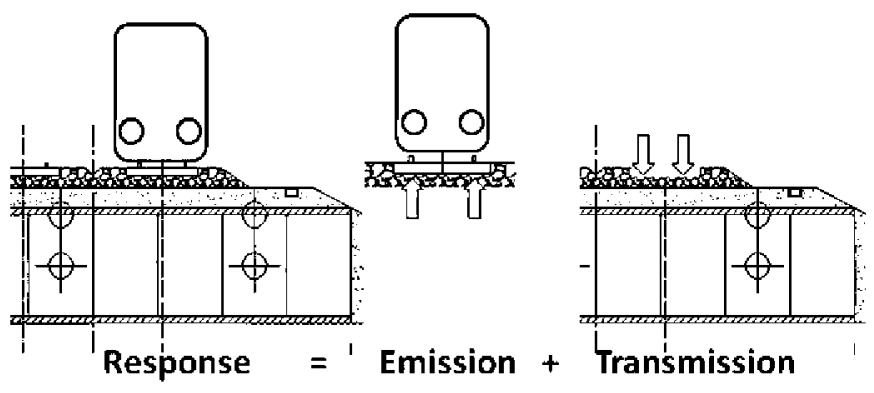

Fig. 8. Two-step method for estimating the structural response.

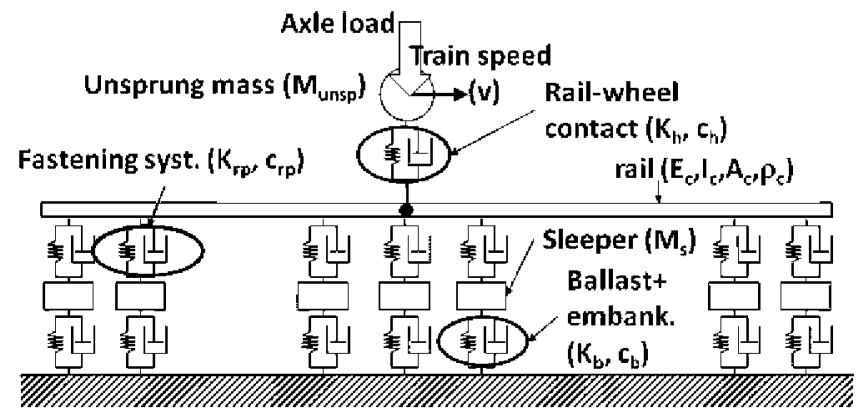

Fig. 9. Sketch of the emission model. 
It is often convenient to perform two separate time history analyses: one considering only the contribution of axle loads and another considering the self equilibrating forces associated with roughness, with each producing reaction force time histories. The total reaction force is then the sum of the results of both analyses. In the first problem, the load is constant; therefore, the time histories for different axle loads can be obtained by scaling. Moreover, considering axle distances and train velocity, time lags can be computed, making it possible to construct the complete history of reaction forces when the train passes (excluding the reaction forces caused by roughness).

\subsection{Transmission model}

Once reaction forces at the source points have been obtained, the remaining elements needed to use Eq. (2), are the impulse response functions $h_{k}(t)$ for each considered source point. In practice, these functions are not calculated because convolution is performed in the frequency domain to take advantage of the properties of the Fourier transform

$$
h_{k}(t) * f_{k}(t)=\int_{-\infty}^{\infty} H_{k}(\omega) \cdot F_{k}(\omega) \mathrm{d} \omega
$$

where $H_{k}(\omega)$ and $F_{k}(\omega)$ are the Fourier transforms of $h_{k}(t)$ and $f_{k}(t)$, respectively.

Thus, instead of the impulse response functions $\left(h_{k}(t)\right)$, their transforms, the transfer functions between the source and receptor points $\left(H_{k}(\omega)\right)$ are calculated. They are obtained through a harmonic analysis, where a unit load is applied to the source, and a response is recorded in the receptor. Calculations are performed for two emission points per sleeper, one placed below each rail. Therefore, for each point for which a response is to be estimated, the number of transfer functions is twice the number of considered sleepers $\left(N_{\text {sleep. }}\right)$

$$
a(t)=\sum_{k=1}^{N_{\text {sleep. }}} \int_{-\infty}^{\infty}\left(H_{k 1}(\omega) \cdot F_{k 1}(\omega)+H_{k 2}(\omega) \cdot F_{k 2}(\omega)\right) \mathrm{d} \omega
$$

For a given frequency, all transfer functions are simultaneously computed by taking advantage of the reciprocity principle. A unit harmonic force is applied at the node at which a response is desired, while displacements are measured at all source points considered. Because of the assumed symmetry of the problem, only half of the geometry is modeled.

A typical FE mesh is presented in Fig. 10. Five different materials were defined: soil, embankment, backfill, ballast and structural concrete. The elements in Fig. 10 are colored according to their construction material.

The mesh contains 20 node solid elements, although in some portions of the backfill, some ten node tetrahedra were used. The model also contains dashpots to avoid the reflection of waves at non-free surfaces. There, the order of the quadratic elements was reduced to linear. At each surface node, three dashpots were placed, one in each direction. Their properties depend on their angles relative to the surface normal direction, i.e., parallel $\left(c_{\text {paral. }}\right)$ or perpendicular $\left(c_{\text {perp. }}\right)$ $[23,24]$

$$
\left\{\begin{array}{l}
c_{\text {perp }}=\rho \cdot c_{p} \cdot A_{e q} \\
c_{\text {paral. }}=\rho \cdot c_{s} \cdot A_{e q}
\end{array}\right.
$$

where $\rho$ is the density of the soil, $c_{p}$ and $c_{s}$ are the speeds of the compression and shear waves, respectively, and $A_{e q}$ is the area of the non-reflecting surface.

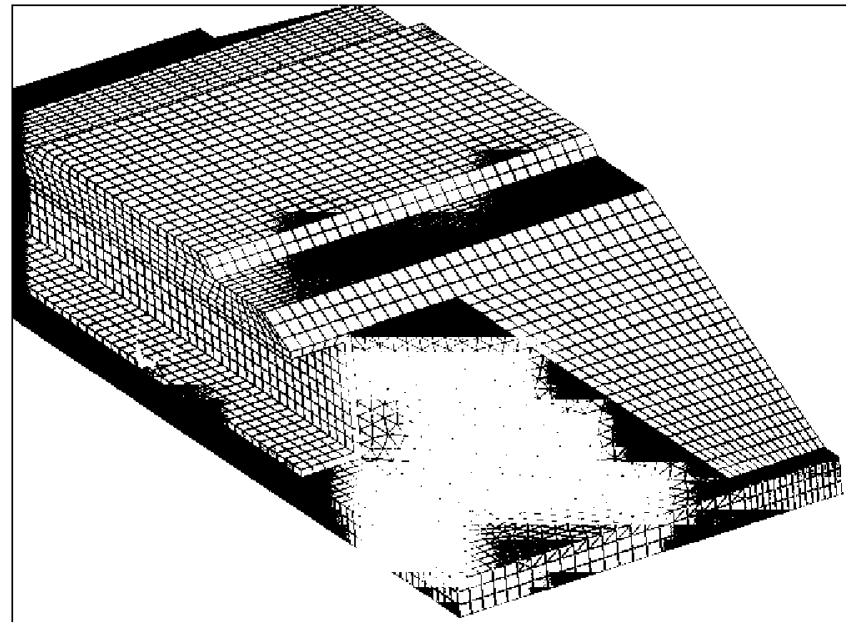

Fig. 10. Solid elements in the mesh of the FE transmission model. 
Element sizes were set such that there are at least four elements per wavelength at $120 \mathrm{~Hz}$, assuming the embankment to be the softest material. The number of degrees of freedom of the model was limited to enable the computer to handle the problem using only RAM memory (the computer used in these calculations had 6 GB of RAM). The model extends for $15.5 \mathrm{~m}$ perpendicular to the track axis on each side and $10.8 \mathrm{~m}$ parallel to the track (spanning 18 sleepers), and it has 1 million degrees of freedom. Time needed for each calculation (one frequency, one source point) was around $2 \mathrm{~h}$.

For each point where the response was to be estimated, the $H_{k}$ functions were computed for values between 0 and $120 \mathrm{~Hz}$ in $4 \mathrm{~Hz}$ increments.

\section{Model fitting}

In this section the fitting procedure is presented. The goal is not to perfectly fit one sample record, but to reproduce the response distribution pattern along the roof-slab, as well as the observed scatter.

First a sensitivity analysis of both the emission and the transmission model revealed the key parameters in model fitting. Then, the fitting itself was performed. The fitting quality will be assessed by considering the energy distribution in the range of $0-120 \mathrm{~Hz}$ of the acceleration record.

\subsection{Transmission model sensitivity}

The key parameters of the transmission model are the material properties. Their values should not be very different from the nominal ones, which are listed in Table 2.

A sensitivity analysis showed that variation in these properties within reasonable bounds leads to transfer functions with narrow differences (i.e., values of the same order of magnitude). In Fig. 11, two plots represent the transfer functions linking forces applied under the sleeper below both rails at midspan, and the acceleration at a point also placed at midspan. The transfer functions obtained using the nominal properties (i.e., those in Table 2) are plotted along with those obtained with slight modifications to the material properties, as listed in Table 3.

In Fig. 11, the transfer functions associated with the nominal values indicate a resonance at approximately $44 \mathrm{~Hz}$. The vibration mode at this frequency is similar to the static deflected shape with one loop in the roof-slab, as shown in Fig. 12(a), where the modulus of the vertical harmonic response at $44 \mathrm{~Hz}$ is plotted. Above this frequency value, the modulus of the transfer functions oscillates around an almost constant level up to $110 \mathrm{~Hz}$, above which it falls monotonically. Within the $44-110 \mathrm{~Hz}$ range, other resonances appear. They are associated with vibration modes with two or more loops along the roof-slab (Fig. 12(b)).

Table 2

Material properties in transmission FEM.

\begin{tabular}{lllll}
\hline Material & E (GPa) & $\rho\left(\mathrm{kg} / \mathrm{m}^{3}\right)$ & $v$ & $c_{s}(\mathrm{~m} / \mathrm{s})$ \\
\hline Soil & - & 1800 & 0.35 & 350 \\
Back-fill & - & 2200 & 0.35 & 900 \\
Embankment & - & 1800 & 0.35 & 200 \\
Ballast & 0.28 & 1800 & 0.4 & - \\
Concrete & 35 & 2500 & 0.4 & - \\
\hline
\end{tabular}

(a)

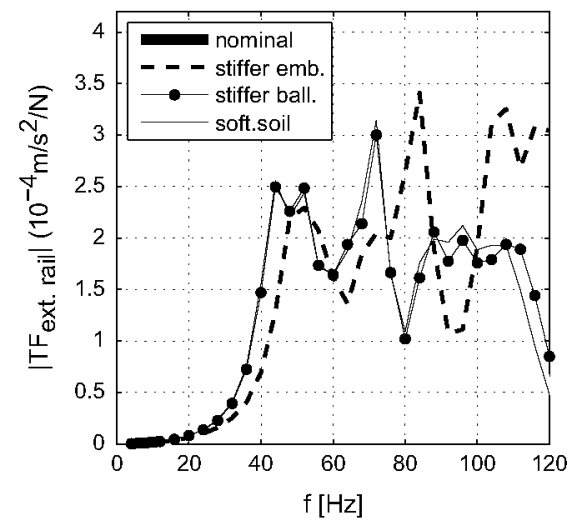

(b)

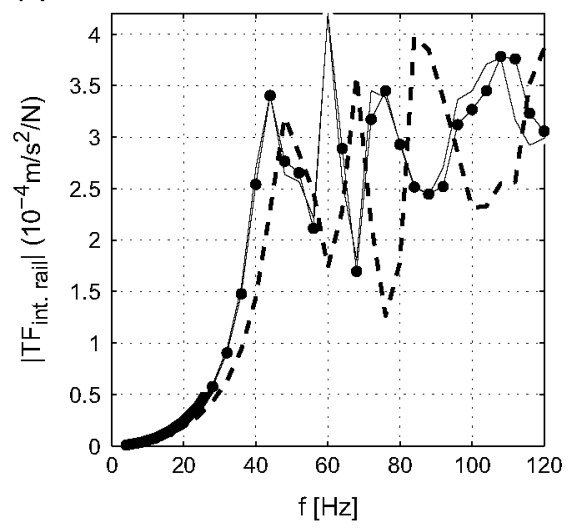

Fig. 11. Force-acceleration transfer functions using different material properties from the sources of the sleeper above the midspan on southbound track to the position of sensor B. (a) Exterior rail, (b) interior rail. 
Table 3

Material properties in the modified transmission FEM.

\begin{tabular}{llll}
\hline Model & Modified property & Nominal value & Modified value \\
\hline Stiffer embankment & $c_{s}$ (emb.) & $200 \mathrm{~m} / \mathrm{s}$ & $300 \mathrm{~m} / \mathrm{s}$ \\
Stiffer ballast & $E$ (ballast) & $280 \mathrm{MPa}$ & $350 \mathrm{MPa}$ \\
Softer soil & $c_{s}$ (soil) & $350 \mathrm{~m} / \mathrm{s}$ & $250 \mathrm{~m} / \mathrm{s}$ \\
\hline
\end{tabular}

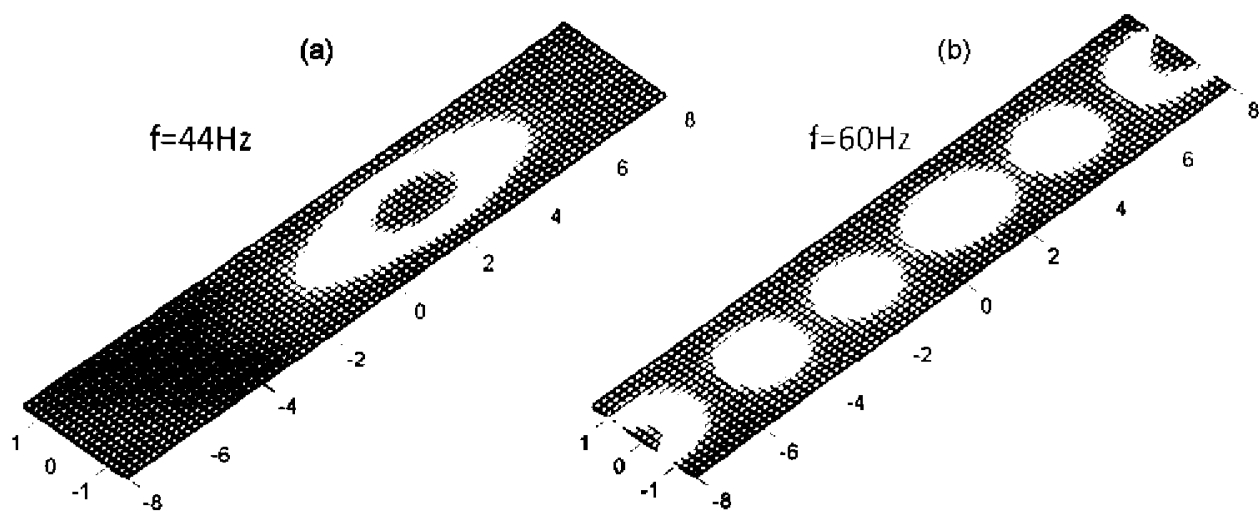

Fig. 12. Vertical displacement magnitudes of the roof-slab arising from harmonic loading applied at the two source points located above the midspan at: (a) $44 \mathrm{~Hz}$ and (b) $60 \mathrm{~Hz}$. The red color indicates higher vertical displacements and the blue color indicates reduced ones. (For interpretation of the references to color in this figure caption, the reader is referred to the web version of this article.)

The transfer functions associated with a softer soil are almost the same as the nominal ones, which indicates that soil properties are of little importance in the response of the roof-slab of this underpass. The case with a stiffer ballast is slightly different, but the differences only clearly appear at frequencies above $80 \mathrm{~Hz}$. Finally, the case with the stiffer embankment is the one that differs the most from the nominal one, although the patterns are similar in both cases. Its resonant frequency is approximately at $48-52 \mathrm{~Hz}$. It can be concluded that the embankment stiffness is the parameter that influences the most the position of the resonance frequency of the box-frame.

\subsection{Emission model sensitivity}

The main unknown in the emission model is roughness, whereas other parameters can be estimated because the rail properties (UIC60), the sleeper's mass $(330 \mathrm{~kg})$ and the fastening system are well known $\left(K_{r p}=180 \mathrm{kN} / \mathrm{mm}\right.$, $C_{r p}=15 \mathrm{kNs} / \mathrm{m}$ ). Additionally, for this preliminary assessment, the springs and dashpots representing the ballast and the embankment above the soil were assigned the following values: $K_{b}=100 \mathrm{kN} / \mathrm{mm}$ and $C_{b}=57 \mathrm{kNs} / \mathrm{m}[25]$.

The key parameter in the Braun and Hellenbroich $(\mathrm{B} \& \mathrm{H})$ roughness model is $G_{r r}\left(n_{0}\right)$. This model was found to accurately represent rail roughness as $G_{r r}\left(n_{0}\right)=1 \times 10^{-9} \mathrm{~m}^{3}$ in the case of high-quality track and as $0.5 \times 10^{-6} \mathrm{~m}^{3}$ for poor-quality track [22]. The model can also be tuned to fit the Class $C$ roughness level given in ISO-3095, using a value of $G_{r r}\left(n_{0}\right)=15 \times 10^{-6} \mathrm{~m}^{3}$, and $\omega=2$ [26]. To assess the influence of this parameter in the acceleration responses measured in the structure, simulations were performed using the three above-mentioned values for $G_{r r}\left(n_{0}\right)$ with $\omega=3.5$ to obtain sample roughness profiles. In all cases, the same train (S-130) and the same speed $(200 \mathrm{~km} / \mathrm{h})$ were considered. For each simulation, two roughness profiles were generated by considering the same spectral density, one for each rail.

Fig. 13 presents the energy distribution of the acceleration signal in one-third-octave bands at sensor position s-B for each roughness level. Plotted values are average ones obtained by considering the responses to eight different couples of unevenness profiles. The plot indicates that roughness is important for frequencies above the $20 \mathrm{~Hz}$ band (i.e., wavelengths below $2.7 \mathrm{~m}$ ) and also allows for an assessment of the influence of the parameter $G_{r r}\left(n_{0}\right)$ because the differences among the acceleration levels are greater than $20 \mathrm{~dB}$ for frequency bands above $40 \mathrm{~Hz}$.

Although the vertical stiffness below each sleeper varies along the track, affected by the presence of the culvert and the transition backfill, all springs and dashpots have been assigned the same values. This simplification was adopted because a more realistic distribution resulted only in slight differences in the acceleration levels at all sensor positions.

It should be pointed out that, from this point on, all acceleration levels are estimated with reference to the one second long window displaying the highest running RMS value. 


\subsection{Model fitting}

Given the small differences found in the sensitivity analysis when tuning the transmission model, the nominal material properties were assumed. Therefore, the model fitting was reduced to obtaining a suitable roughness profile. It may be argued that inaccuracies in modeling may be hidden by roughness calibration [27]. However, that is not the case in the whole frequency range. The lower one has been proven to be unaffected (c.f. Fig. 13).

The emission model was fitted by minimizing the differences between predictions at sensor position $\mathrm{s}-\mathrm{B}$, and average measured values. The objective function was set based on those differences. Three variables were considered in the optimization problem. First, the stiffness of the spring elements below the sleepers $\left(k_{b}\right)$. Second, parameter $G_{r r}\left(n_{0}\right)$ in the $\mathrm{B} \& \mathrm{H}$ model. The third parameter stems from an additional hypothesis on the roughness profile that is explained next.

Fig. 13 indicates that unevenness profiles generated with the B\&H model lead to either too low levels in the $25-40 \mathrm{~Hz}$ range, or too high levels above $40 \mathrm{~Hz}$. Thus it has been assumed that roughness spectral density has the form indicated in Eq. (3), with $\omega=3.5$, and two different $G_{r r}\left(n_{0}\right)$ values depending on the wavenumber. Therefore the unevenness spectral density is assumed to display a vertical discontinuity, the magnitude of which $\left(A_{G}\right)$ is the third variable parameter of the optimization problem. The form of the proposed spectral density has arisen naturally during the fitting process, and may be supported by results in the literature.

The discontinuity $\Delta_{G}$ is set at $\lambda=1.3 \mathrm{~m}$. This limit is associated with a frequency close to $45 \mathrm{~Hz}$ for $v=200 \mathrm{~km} / \mathrm{h}$, which is approximately the boundary between the $40 \mathrm{~Hz}$ and the $50 \mathrm{~Hz}$ bands. For short wavelengths $(\lambda \leq 1.3 \mathrm{~m})$, a good-quality roughness seems appropriate for fitting purposes. De Roeck et al. [28] presented similar conclusions for $\lambda \leq 0.31 \mathrm{~m}$ from in-situ measurements of a high-speed railway line in Belgium.

However, this roughness level seems to be unsuitable for wavelengths in the $1.3-2.5 \mathrm{~m}$ range. These wavelengths are shorter than those associated with axle loads and may be associated with, for example, differences in sleeper vertical alignment or wheel roughness. Kogut et al. [26] used a roughness level equivalent to ISO-3095 class $C$ to fit measurements in the range of frequencies between 15 and $40 \mathrm{~Hz}$. This frequency range, for a speed of $300 \mathrm{~km} / \mathrm{h}$, corresponds to wavelengths between 1.1 and $5.5 \mathrm{~m}$. This roughness level, as indicated in the previous section, is above the level usually assigned to poor-quality rails in the B\&H model. Sheng et al. [29], and Esveld [30] presented spectral densities obtained from on-site measurements that are also much higher than the above-mentioned poor-quality B\&H level.

The variation ranges considered for the three variables in the optimization problem are presented in Table 4. Bounds for $k_{b}$ and $G_{r r}\left(n_{0}\right)$ were set based on usually reported values. In the case of $A_{G}$, the range was widened after some trials in order to ensure that the optimum value was included in it.

As two unevenness profiles generated from the same spectral densities result in different values of acceleration levels, predictions will be averaged. For each combination of the three variables a set of ten different roughness profiles have been

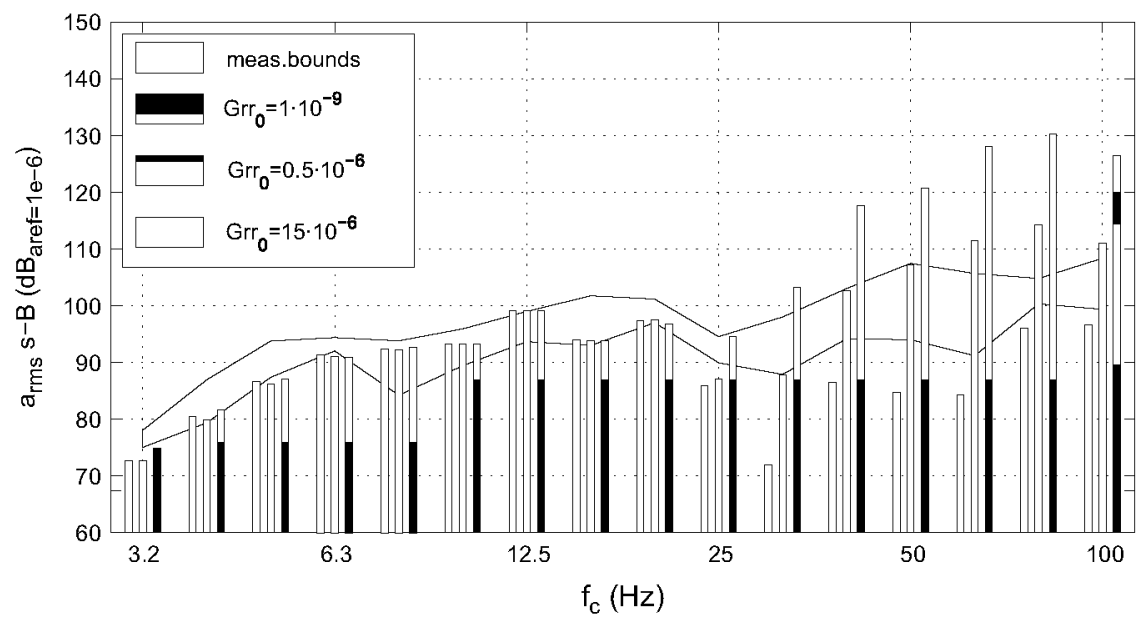

Fig. 13. Comparison of average acceleration levels for different roughness levels.

Table 4

Model fitting. Ranges of variation of emission model parameters.

\begin{tabular}{lrrr}
\hline Variable & Min. value & Max. value & Increment \\
\hline$k_{b}(\mathrm{kN} / \mathrm{m})$ & 80 & 150 & 10 \\
$G_{r r}\left(n_{0}\right)\left(10^{-9} \mathrm{~m}^{3}\right)$ & 1 & 31 & 5 \\
$\Delta_{G}$ & 100 & 1500 & 100 \\
\hline
\end{tabular}


generated for each rail. Then a set of ten responses are estimated, leading to sets of ten values for each one-third-octave bands, which are averaged in $\mathrm{dB}$ scale.

In the ranges of considered values, the optimization problem is not convex. It has been solved using a brute force approach, where for each variable, a reduced set of values are considered and all combinations are tested. The sets are defined by choosing equally spaced values between the lower and the upper bounds (both included), considering the increments presented in Table 4.

Some tendencies arouse, reducing the extent of optimal combined values. The choice among those latter values was guided by a second optimization problem based on acceleration at sleepers.

If the emission model is fitted using a response quantity which calculation involves also the transmission model, the question may arise about possible bias introduced by the second one. In the second optimization problem, the objective function is set similar to the previous one, but defined based on differences between acceleration levels at the sleepers.

This second additional optimization problem has led to the final optimum values: $k_{b}=130 \mathrm{kN} / \mathrm{mm}, G_{r r}\left(n_{0}\right)=1 \times 10^{-9} \mathrm{~m}^{3}$, and $A_{G}=1100$. The roughness profile is, as expected, in the good quality range for short wavelengths, and higher for long ones.

A comparison of measurement and predictions considering the optimum values is presented in Fig. 14. Fig. 14(a) displays measurements and predictions at sleepers. Predicted acceleration levels follow quite well the pattern of measurements, and maximum differences are in the order of $10 \mathrm{~dB}$. Together with the average values, the set of ten sample values are presented in order to allow also assessing the scatter in predictions.

Fig. 14(b) displays the same comparison at sensor position B. In this case the agreement between measured and calculated values is quite good for the whole range of frequencies. The scatter in predictions is similar to the one in measurements above $20 \mathrm{~Hz}$. Below this frequency the model leads to almost deterministic values regardless of the roughness profile samples considered for the simulation.

\subsection{Predictions and scatter using the fitted model}

The quality of the fitted model is now tested for other positions of the roof slab. Fig. 15 shows comparisons of measured and predicted acceleration levels at each sensor position for S-130 trains at $200 \mathrm{~km} / \mathrm{h}$ going northbound. Ten unevenness

(a)

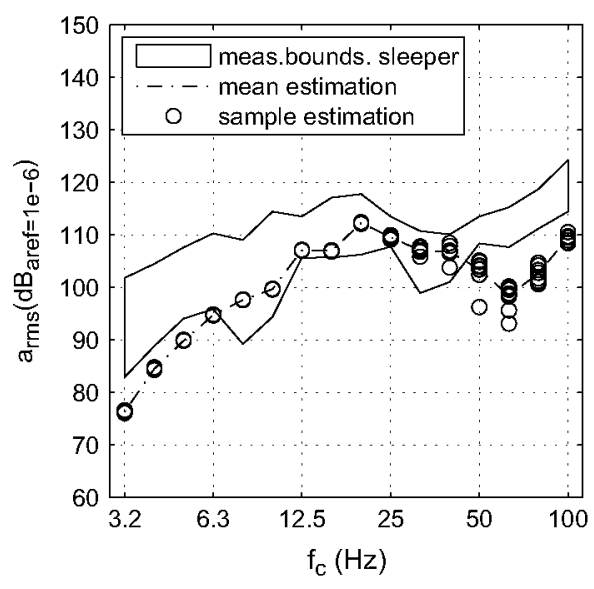

(b)

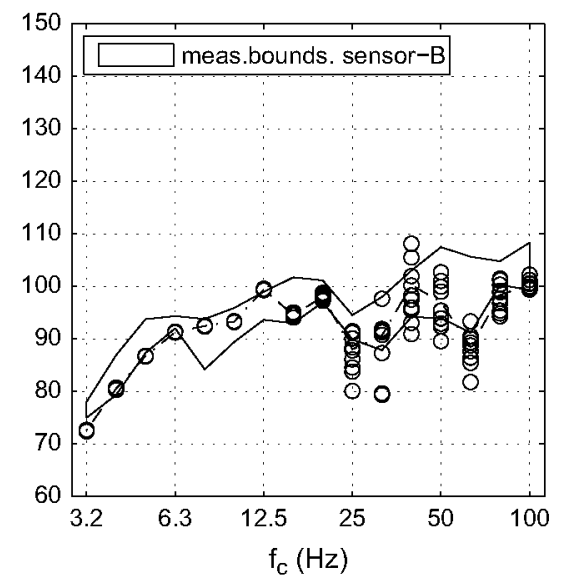

Fig. 14. Measurements against estimations at: (a) sleeper, (b) sensor position B. Train S-130, $v=200 \mathrm{~km} / \mathrm{h}$ southbound.

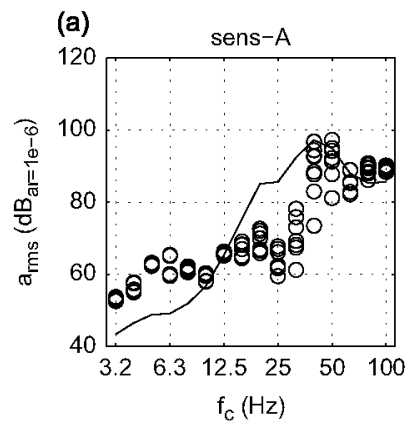

(b)

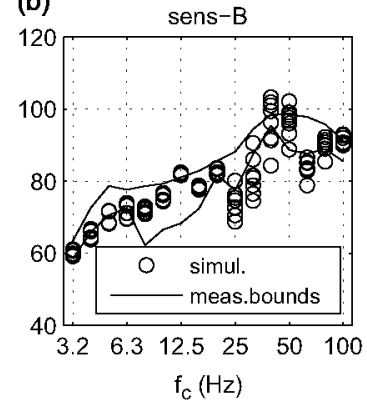

(c)

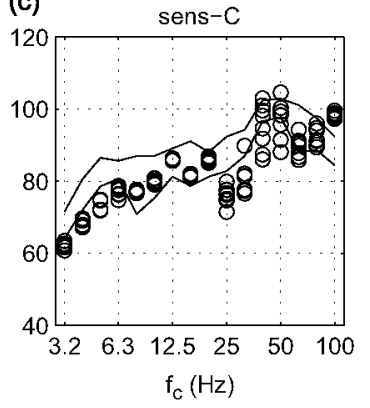

Fig. 15. Comparison of the scatter in the measurements with the predictions for each sensor position: (a) sensor A, (b) sensor B and (c) sensor C. Train $\mathrm{S}-130, v=200 \mathrm{~km} / \mathrm{h}$ northbound. 


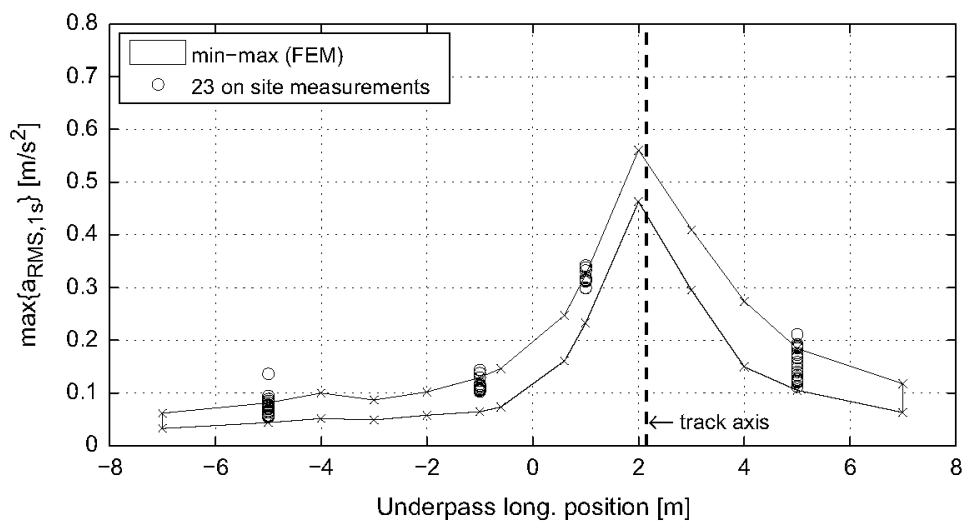

Fig. 16. Calculated response distribution along the roof-slab midspan compared with the measured values. Train $\mathrm{S}-130, v=200 \mathrm{~km} / \mathrm{h}$.

profiles were generated for this plot. Results indicate that both the average levels and the scatter are well predicted at sensor positions $B$ and $C$.

At sensor position A, the one displaying the lowest response values, the accuracy diminishes below $40 \mathrm{~Hz}$, with no clear pattern. However, deviations are not larger than around $20 \mathrm{~dB}$, and these frequency bands are less important in the overall response.

These comparisons indicate that, at points close to the occupied track, the energy content of the acceleration records are well predicted in the whole range of frequency bands between 0 and $100 \mathrm{~Hz}$. At distant points, this is also true at least in frequency bands displaying the most of the energy. Therefore the energy content of the signal seems to be well predicted by the model.

From this point, attention is turned to predictions along the entire roof slab. The model is used to predict the response at midspan along the longitudinal axis of the culvert, that is, perpendicular to the track axis. For the sake of clearness, a single scalar response magnitude will be presented: the maximum value of RMS acceleration time histories calculated according to Eq. (1). This response quantity provides a measure of the energy content of the signal, and has a well-known relationship with spectral densities.

Fig. 16 displays predictions of maximum RMS values together with measurements along the culvert's midspan for S-130 trains at $200 \mathrm{~km} / \mathrm{h}$. Measurements include both northbound and southbound ones. A set of 10 simulations were performed, and responses were estimated at 14 positions. For the sake of clearness, only extreme values are displayed and straight lines have been used to join them.

Fig. 16 shows that the band-clustering simulation results are in good agreement with the measurements, and allows assessing the differences in response levels along the roof's midspan. It also allows the location, at least approximatively, of the point with the highest response (close to the point below the track axis).

\section{Simplified 2D model}

The mesh shown in Fig. 10 provides high calculation times, which alone is sufficiently important to exclude any parametric study with such a model. As described in this section, our next aim was to prove that it is possible to obtain useful results with simpler models [14].

For example, it is possible to use a $2 \mathrm{D}$ model to represent the portion of the structure with the highest demand. As described in the previous section, this region was observed to be just below the track hosting the traffic. The model is sketched in Fig. 17 and consists of plane stress elements having variable thickness. At the sleeper soffit, the width is fixed to be equal to the effective length of the sleeper, which is approximately $2.3 \mathrm{~m}$. The elements representing the underpass structure are all assumed to have fixed thicknesses $\left(U_{w}\right)$. Below the highest point of the structure, the elements representing the embankment, the backfill and the soil are assumed to increase in thickness in a 1:4 proportion, as indicated by both the Spanish construction code [31] and the Eurocode [13]. Variable-thickness plane stress elements have previously been used to model embankments [32].

A mesh of the model is presented in Fig. 18. The same materials used in the 3D model are also included in this one. Quadrilateral 8-node elements of serendipity type are used, except at the boundaries, where the order has been reduced, as in the 3D model. A nonreflecting Lysmer-type boundary is also included, and special attention is paid to element size to ensure that there are at least five elements per wavelength at $120 \mathrm{~Hz}$ with the softest material.

The reduction in computational cost can be assessed by comparing the number of degrees of freedom in each model. The 2D model has approximately 90,000 degrees of freedom, which is approximately one-tenth as many as the 3D model.

The parameter that enables model updating is the width of the elements representing the underpass $U_{w}$. The model is considered fitted when it provides peaks in acceleration RMS time histories equal to those obtained with the 3D model at the response point under highest demand described in the previous section (i.e. point $+2 \mathrm{~m}$ in Fig. 16). For this process, a 


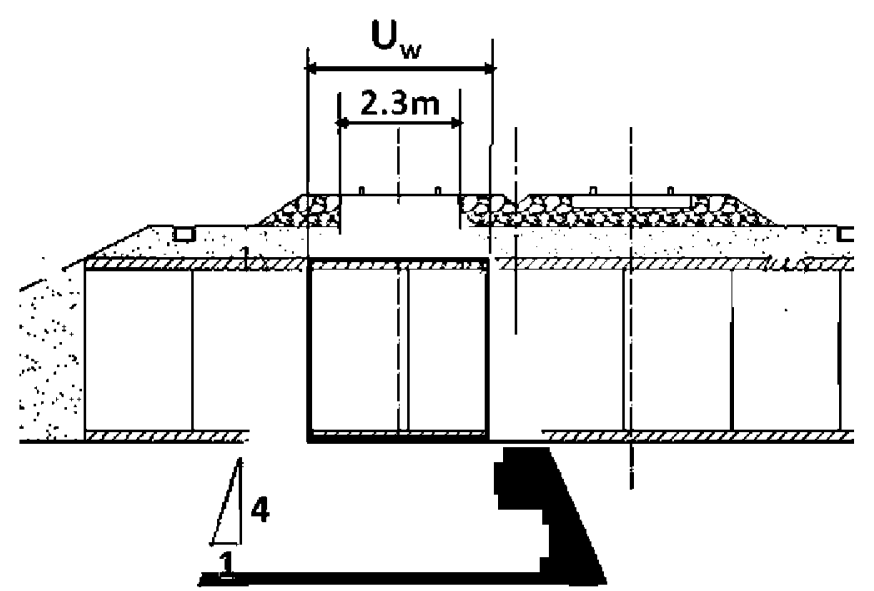

Fig. 17. Two-dimensional FE model concept with unknown parameter $U_{w}$ (underpass thickness).

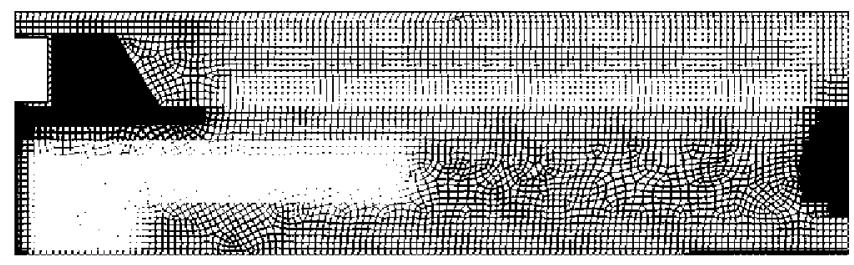

Fig. 18. One half of the $2 \mathrm{D}$ model $\mathrm{FE}$ mesh.

(a) $\times 10^{-3}$

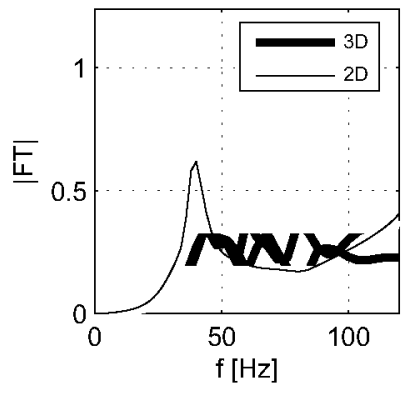

(b)

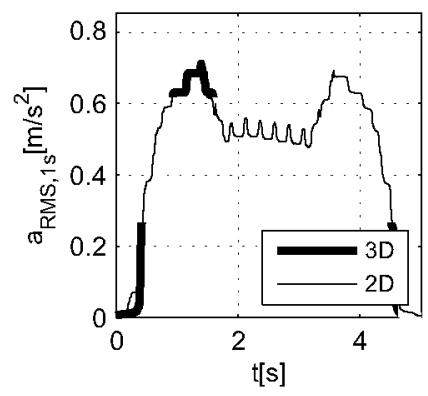

(c)

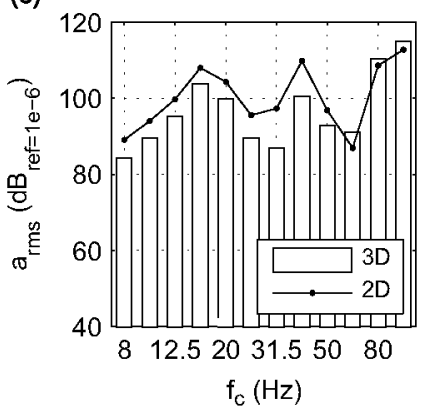

Fig. 19. Comparison of results using $2 \mathrm{D}$ and $3 \mathrm{D}$ transmission models: (a) transfer functions, (b) RMS acceleration and (c) acceleration levels in one-thirdoctave bands.

single roughness profile was simulated to exclude any influence on discrepancies between the models. The tuning process provided a value of $U_{w}=2.5 \mathrm{~m}$.

Fig. 19 shows a comparison of the predictions using the 2D model and the 3D model from three different points of view. As desired, both models provided the same RMS peak values (Fig. 19(b)), although the RMS time histories showed small differences (less than 10 percent) in the middle portion of the record. The energy content (Fig. 19(c)) was similar in the highest frequency range (bands above $60 \mathrm{~Hz}$ ), whereas the simplified $2 \mathrm{D}$ model provided the highest levels below that range.

The discrepancies may be explained with reference to Fig. 19(a), where transfer functions considering source points above the midspan are compared. Considering the behavior of the box-frame upper slab, 2D models can only reproduce beam type resonant modes. The 3D model has plate type modes, the first one being similar to a beam type mode in the longitudinal direction (c.f. Fig. 12(a)). In this case the 2D model does not accurately reflect the resonant peak. However, it provides a good approximation of the average level from 40 to $100 \mathrm{~Hz}$, and this is a key factor because, in the recorded signals, the greatest amount of energy is in that range.

A comparison of the transfer functions in Fig. 19(a) also indicates that the fit would have been different if other frequency ranges were of interest. For example, if the focus had been on displacements or strains, only low frequencies would be important, thus reducing the range for model updating to the area below the first resonance. With $U_{w^{\prime}}=2.5 \mathrm{~m}$ the 
2D model provides a higher response magnitude in that area; therefore, wider elements, i.e., a larger $U_{w}$ parameter, would be needed for suitable displacement modeling.

\section{Conclusions}

This work presents a set of measurements and models that provide a method of quantifying the dynamic behavior of underpasses. The measurements show that acceleration scatter is large. Furthermore, the response distribution along the underpass axis was found to be nonuniform, and the relative position between the track axis and sensor is important because of the plate effect of the roof-slab.

The use of a substructuring method allowed us to model the dynamic behavior of this structure using a set of two finite element models: one for the superstructure and another for the structure-embankment-soil ensemble. These models yielded an accurate reproduction of the acceleration levels in the structure's roof-slab.

Although it exceeds the intended scope of the model, its accuracy has also been checked in the superstructure. Results at sleepers indicate that improvements should be introduced if an accurate estimation at low frequencies was sought there.

The emission model was fitted using a modified Braun and Hellenbroich model, where we differentiated two wavelength ranges: one below $1.3 \mathrm{~m}$, in which the roughness was found to fit the high-quality rail reference value well, and a second one for wavelengths above $1.3 \mathrm{~m}$, where the roughness levels are much higher, which was closer to the poorquality reference value.

Although the three-dimensional transmission model is useful for capturing differences across the track axis, a twodimensional model was shown to be able to represent the key features and the order of magnitude of the running RMS acceleration values, while displaying some differences in the signal energy distribution along frequencies. However, it may be useful for parametric studies or practical design purposes, knowing about its limitations in cases where higher plate modes are important.

\section{Acknowledgments}

This research was sponsored by Spanish Ministerio de Fomento, Direccion General de Ferrocarriles, under contract No. A-V-ENC-E-119, and supervised by Eng. Julian Santos and Eng. Antonio Corral, to whom the authors wish to express their gratitude. The authors wish also to thank the reviewers for their valuable comments and suggestions to improve the quality of the paper.

\section{References}

[1] R. Willis, Appendix to the Report of the Commissioners Appointed to Inquire into the Application of Iron to Railway Structures, H.M. Statinery Office, London, 1849.

[2] G.G. Stokes, Discussion of a differential equation related to the breaking of railway bridges, Transactions of the Cambridge Philosophical Society 8 (Part 5) (1867).

[3] S.P. Timoshenko, Erzwungene Schwingungen Prismatisher Stäbe (Forced vibrations of prismatic beams), Zeitschrift für Mathematik und Physik $59(1911)$.

[4] C.E. Inglis, A Mathematical Treatise on Vibrations in Railway Bridges, Cambridge University Press, 1934.

[5] A. Hillerborg, Dynamic Influences of Smoothly Running Loads on Simply Supported Girders, Kungliga Tekniska Högskolan, Stockholm, 1951.

[6] J.M. Biggs, Structural Dynamics, McGraw-Hill, 1964.

17] L. Fryba, Vibration of Solids and Structures under Moving Loads, Noordhoff, 1972

[8] D214 Committee, Ponts rails pour vitesses sur $200 \mathrm{~km} / \mathrm{h}$. Rapport Final (Railway bridges for speeds above $200 \mathrm{~km} / \mathrm{h}$, Final Report), European Rail Research Institute, 2000

[9] P. Museros, M.L. Romero, A. Poy, E. Alarcon, Advances in the analysis of short span railway bridges for high-speed lines, Computers and Structures $80(2002) 2121-2132$.

[10] G. Abdel-Sayed, B. Bakht, L.G. Jaeger, Soil-steel Bridges: Design and Construction, McGraw Hill, 1994.

[11] Transportation Research Board, Culverts: Analysis of Soil-Culvert Interaction and Design, Transportation Research Record 1008, Washington DC, 1985.

[12] EN1990, EUROCODE 0, Basis of structural design, Annex A2.

[13] EN1991, EUROCODE 1, Actions on Structures. Part2: Traffic loads on Bridges, 2002.

[14] A. Fraile, L. Hermanns, F. Chirino, E. Alarcon, Dynamic effects of high speed trains on underpasses, Proceedings ICCST02 Sixth Conference on Computational Structures Technology, Civil-Com Press, Edinburgh, UK, 2002.

[15] P. Galvin, J. Dominguez, High-speed train-induced ground motion and interaction with structures, Journal of Sound and Vibration 307 (2007) $755-777$

[16] A. Romero, J. Dominguez, P. Galvin, 3D numerical analysis of train-induced vibrations on short bridges considering vehicle-track-structure-soil dynamic interaction, Proceedings of the 8th International Conference on Structural Dynamics, EURODYN 2011, Leuven, Belgium, 4-6 July 2011.

[17] J. Vega, L. Hermanns, E. Alarcon, A. Fraile, Dynamic effects on culverts for high speed trains, Congresso CMNE2011, Coimbra, Portugal, 2011.

[18] E. Alarcon, J. Vega, E. Montañes, A. Fraile, Dynamic effects on culverts for high speed trains, Workshop on Dynamics, Structural and Earthquake Engineering: Research and Practice, Ispra, Italy, 16 July 2010.

[19] H. Xia, N. Zhang, R. Gao, Experimental analysis of railway bridge under high-speed trains, Journal of Sound and Vibration 282 (2005) 517-528.

[20] Federal Transit Administration, Transit noise and vibration impact assessment, May 2006, Report Number FTA-VA-90-1003-06.

[21] R.R. Craig, C.C. Bampton, Coupling of substructures for dynamic analysis, American Institute of Aeronautics and Astronautics Journal 6 (7) (1968) $1313-1319$. 
[22] H. Braun, T. Hellenbroich, Messergebnisse von Strassenunebenheiten (Measurement results of road irregularities), VDI Berichte 877, VDI-Verlag (1991), Dusseldorf, Germany. pp. 47-80.

[23] J. Lysmer, R.L. Kuhlemeyer, Finite dynamic model for infinite media, Journal of Engineering Mechanic Division, ASCE 95 (1969) $859-877$.

[24] G. Gazetas, Simple physical methods for foundation impedances, in: P.K. Banerjee, R. Butterfield (Eds.), Dynamic Behaviour of Foundations and Buried Structures, Elsevier Applied Science, New York, 1987.

[25] C. Esveld, A. De Man, Use of railway track vibration behaviour for design and maintenance, IABSE Symposium, Antwerp 2003 , pp. 39-45(7).

[26] J.P. Kogut, G. Lombaert, S. François, G. Degrande, W. Haegema, L.Karl, High speed train induced vibrations: in-situ measurements and numerical modeling, Tenth International Congress on Sound and Vibration, July 2003, Stockholm, Sweden.

[27] G. Lombaert, G. Degrande, Ground-borne vibration due to static and dynamic axle load of InterCity and high-speed trains, Journal of Sound and Vibration 319 (2009) 1036-1066.

[28] G. De Roeck, J. Maeck, A. Teughels, Validation of numerical models by experiments on a high-speed railway bridge in Antoing, IABSE Symposium: Structures for High-Speed Railway Transportation, August 2003, pp. 306-307.

[29] X. Sheng, C.J.C. Jones, D.J. Thompson, A theoretical model for ground vibration from trains generated by vertical track irregularities, Journal of Sound and Vibration $272(2004) 937-965$.

[30] C. Esveld, Modern Railway Track, 2nd Ed. MRT Productions, Duisburg, Germany, 2001, pp. 544-545.

[31] Ministerio de Fomento, Instrucción sobre las acciones a considerar en el proyecto de puentes de ferrocarril (Code on design actions for railway bridges), Madrid, 2007.

[32] A.W.M. Kok, Finite element models for the steady state analysis of moving loads, Heron 45 (1) (2000). ISSN 0046-7316. 